\title{
Associations Between Pathogen-Specific Cases of Clinical Mastitis and Somatic Cell Count Patterns
}

\author{
Y. de Haas, ${ }^{1}$ R. F. Veerkamp, ${ }^{1}$ H. W. Barkema, ${ }^{2}$ Y. T. Gröhn, ${ }^{3}$ and Y. H. Schukken ${ }^{3}$ \\ ${ }^{1}$ Institute for Animal Science and Health, ID-Lelystad, \\ 8200 AB Lelystad, The Netherlands \\ ${ }^{2}$ University of Prince Edward Island, Atlantic Veterinary College, \\ Department of Health Management, Charlottetown, PEI, Canada C1A 4P3 \\ ${ }^{3}$ Cornell University, College of Veterinary Medicine, \\ Department of Population Medicine and Diagnostic Sciences, \\ Ithaca, NY 14853
}

\begin{abstract}
Associations were estimated between pathogen-specific cases of clinical mastitis (CM) and somatic cell count (SCC) patterns based on deviations from the typical curve for SCC during lactation and compared with associations between pathogen-specific CM and lactation average SCC. Data from 274 Dutch herds recording CM over an 18-mo period were used. Pathogens found were Staphylococcus aureus, coagulase-negative staphylococci, Escherichia coli, Streptococcus dysgalactiae, Streptococcus uberis, streptococci other than Strep. dysgalactiae and Strep. uberis, and culture-negative samples. The dataset contained 245,595 test-day records on SCC, recorded in 24,012 lactations of 19,733 cows of different parities. Pattern definitions were based on three or five consecutive test-day records. The patterns differentiated between a short or longer period of increased SCC and also between lactations with and without recovery. Logistic regression was applied to identify associations between presence of patterns and occurrence of pathogens. Occurrence of overall CM in a lactation is equally or even more accurately predicted by the presence of SCC in that lactation, than by a lactation average SCC of more than 200,000 cells/mL. Patterns can also distinguish between chances of risk for specific mastitis-causing pathogens. Clinical $E$. coli mastitis was significantly associated with the presence of a short peak in SCC, whereas Staph. aureus was associated with long increased SCC. Streptococcus dysgalactiae was not strongly associated with any of the defined patterns of peaks in SCC, and no single unambiguous pattern was found for Strep. uberis.
\end{abstract}

(Key words: somatic cell count, pattern, lactation curve, clinical mastitis)

Received July 2, 2002.

Accepted May 8, 2003.

Corresponding author:Y.de Haas; e-mail:Y.deHaas@id.wag-ur.nl.
Abbreviation key: $\mathbf{C M}=$ clinical mastitis, $\mathbf{C S C C}=$ corrected SCC, $\mathbf{H F}=$ Holstein-Friesian, $\mathbf{O R}=$ odds ratio, SCC200 = lactation average of SCC of more or less than 200,000 cells $/ \mathrm{ml}$, SCM = subclinical mastitis .

\section{INTRODUCTION}

Average lactation values for SCC are generally used in mastitis control programs and for genetic improvement of udder health. However, these average values ignore variation in SCC during lactation. Curves for SCC during lactation decline to nadir before 60 DIM and increase during the remainder of lactation (Wiggans and Shook, 1987; Schutz et al., 1990; Weller et al., 1992; De Haas et al., 2002a). Clinical and subclinical mastitis can cause deviations from this typical curve of SCC, and it has been shown that specific pathogens involved in cases of clinical mastitis (CM) affect the curve differentially (De Haas et al., 2002a).

Using test-day records of SCC instead of lactation average of SCC increases the possibilities of identifying deviations from the typical curve of SCC during lactation. These deviations might characterize mastitiscausing pathogens. If so, analyzing test-day records of SCC can be more useful in attempting to decrease the prevalence of subclinical mastitis (SCM) and the incidence of CM than the lactation average of SCC. An effective use of SCC test-day records might be achieved by defining patterns of peaks in SCC during the lactation. If these patterns of peaks in SCC provide information on 1) the pathogen distribution on a farm, 2) the success of therapy, and 3) the status of immunity of the cows, these patterns might be better tools to use in mastitis control programs or for genetic selection programs. Management can then be directed specifically on lowering the incidence of pathogen-specific CM, or shortening the duration of infection. Furthermore, decreased genetic susceptibility to the full scope of mastitis-causing pathogens might be accomplished, which cannot completely be achieved by genetic selection on 
lower lactation average SCC (Nash et al., 2000; De Haas et al., 2002b). Eventually, this all helps to limit the losses due to CM.

Before the patterns of peaks in SCC can be used for health management on farms or for genetics, we first have to find out if patterns of peaks in SCC do differ from the lactation average SCC. Therefore, the overall objectives of this study were: 1) to define several patterns of peaks in SCC and then, 2) to test their sensitivity and specificity, and, 3) to estimate their associations with occurrence of pathogen-specific cases of CM, also in comparison with the lactation average of SCC.

\section{MATERIALS AND METHODS}

\section{Herds}

Records on CM were available from a longitudinal prospective cohort study from December 1992 to June 1994 on 274 Dutch farms (Barkema et al., 1998). Lactating cows were housed in free-stall barns, and milking parlors were double herringbone or two-sided open tandem shape. Herds participated in a milk recording system, and annual milk production quotas were between 300,000 and $900,000 \mathrm{~kg}$. The national milk recording system (NRS, Arnhem, The Netherlands) provided information from a three or four weekly milk recording system. A record included national cow identification, breed, date of milk recording, date of calving, date of drying off, test-day milk yields (kilograms of milk, fat, and protein) and SCC (cells $/ \mathrm{ml})$. The main breeds were Holstein-Friesian (HF), Dutch-Friesian, and MeuseRhine-Yssel.

\section{Sampling}

Epidemiological studies often depend on farmer-observed disease incidence, introducing a possible bias caused by variation between farmers in diagnostic criteria. Farmer-diagnosed CM was analyzed in this study. Lam et al. (1993) concluded that the diagnostic capability of farmers does not have a negative influence on the validity of farmer-diagnosed CM. Farmer-diagnosed $\mathrm{CM}$, therefore, seems to be a useful tool in epidemiological studies on CM.

Selection of herds and aseptic sampling procedures have been described previously (Barkema et al., 1998). Data collection of milk samples of quarters with CM depended heavily on the willingness of farmers. Therefore, farmers were continuously encouraged, as described by Barkema et al. (1998). During the study period, farmers took milk samples from all quarters that, in their opinion, had clinical signs of mastitis. Samples were stored in a freezer at the farm (at approximately $-20^{\circ} \mathrm{C}$ ) and were collected for bacteriological examination at intervals of 6 to $8 \mathrm{wk}$. Bacteriological culturing of milk samples was performed according to the standards of the National Mastitis Council (Harmon et al., 1990). Briefly, $0.01 \mathrm{~mL}$ was cultured and, for each culture, the number of colony-forming units of each of the bacterial species was counted. Collected data contained information on national cow identification number, date of mastitis occurrence, infected quarter, and result of bacteriological culturing of milk sample. Seven groups of pathogens were defined based on their incidence in the data: Staphylococcus aureus, CNS, Escherichia coli, Streptococcus dysgalactiae, Streptococcus uberis, streptococci other than Strep. dysgalactiae and Strep. uberis, and culture-negative samples. Pathogen-specific CM was determined on lactation level. Pathogen-specific cases of CM were scored as categorical traits, so when all cases of CM in a lactation were caused by one of the above-mentioned seven pathogens, a 1 was registered for this particular pathogen, otherwise it was scored as 0 . The group of remaining cases of $\mathrm{CM}$ consisted of all lactations in which 1) cases of $\mathrm{CM}$ were associated with any other pathogen or mixed cultures or 2) consecutive cases of $\mathrm{CM}$ were not caused by the same pathogen. In total, 3393 lactations were recorded with cases of CM before 450 DIM (Table 1).

\section{Data Selection}

Originally, phenotypic records on CM and bacteriological characterization were available on 49,529 lactations that had been recorded for at least $1 \mathrm{~d}$ during the study. Records of cows with unknown pedigree, or with extreme ages at calving, were deleted. This reduced the dataset to 47,563 lactations (De Haas et al., 2002b). For the present study, only lactations of cows that had calved after the starting date of the study on farm were included in the dataset, resulting in a dataset with only lactations that were recorded in the study from calving onwards. This criterion was set to ensure that no previous cases of $\mathrm{CM}$ had occurred within the same lactation, and the dataset was reduced to 26,427 lactations. Lactations with fewer than six recordings for SCC were deleted from the dataset, to enable sufficient time for a complete pattern to be present. The final dataset consisted of 24,012 lactations from 19,733 cows. Somatic cell count was recorded on 245,595 test days before 450 DIM.

\section{Definition of Patterns}

To determine the patterns of peaks in SCC, SCC was expressed relative to $\mathrm{SCC}$ in lactations without $\mathrm{CM}$ and SCM (De Haas et al., 2002a), by first estimating SCC 
Table 1. Total number of lactations with no clinical mastitis (CM) and with pathogen-specific CM (total), number of lactations where consecutive test-day records for SCC showed one of the newly defined patterns in SCC (patterns 1 to 4), ${ }^{1}$ and number of lactations with lactation average SCC of higher than 200,000 cells/ $\mathrm{mL}(\mathrm{SCC} 200)$.

\begin{tabular}{lrcrrrr}
\hline & Total & Pattern 1 & Pattern 2 & Pattern 3 & Pattern 4 & SCC200 \\
\hline No clinical mastitis & 20,619 & 1,950 & 246 & 2,157 & 443 & 4,758 \\
Staphylococcus aureus & 394 & 57 & 18 & 84 & 52 & 291 \\
Coagulase-negative staphylococci & 117 & 14 & 5 & 20 & 13 & 50 \\
Escherichia coli & 624 & 156 & 17 & 157 & 25 & 264 \\
Streptococcus dysgalactiae & 220 & 51 & 7 & 58 & 10 & 137 \\
Streptococcus uberis & 159 & 35 & 6 & 39 & 15 & 95 \\
Other streptococci & 185 & 45 & 3 & 51 & 17 & 98 \\
Culture-negative samples & 493 & 88 & 9 & 99 & 18 & 174 \\
Other pathogens & 1,201 & 265 & 29 & 291 & 118 & 728 \\
Total & 24,012 & 2,661 & 340 & 2,956 & 711 & 6,595 \\
\hline
\end{tabular}

${ }^{1}$ Pattern 1: low-high-low; pattern 2: low-higher-high-lower-low; pattern 3: low-no restrictions-high-no restrictions-low; pattern 4: low-high-high-high-high.

on each DIM of these lactations with a spline function (Gilmour et al., 2002). Usually, a spline function is used for smoothing data points, and the function allows maximum flexibility and assumes no prescribed curvature (Gilmour et al., 2002). Secondly, these estimates were subtracted from the SCC test-day records for each DIM value. The procedure was carried out separately for heifers and multiparous cows, and this calculated value for SCC is referred to as the corrected SCC (CSCC). Because De Haas et al. (2002a) only used SCC up to 308 DIM, SCC was extrapolated from 309 to 450 DIM by adding the average daily increase in SCC from 100 to 300 DIM to the calculated SCC on the previous day. Here, the assumption was made that milk yield showed a linear association with DIM at the end of the lactation (>309 DIM), so SCC could be linearly extrapolated with DIM.

Five SCC patterns were defined and distinctions were made between lactations with short or longer periods of increased CSCC, and also between lactations with and without recovery within three or five test-day recordings. A recovery is classified by a recording of a low CSCC after a rise in CSCC. Pattern 1 describes a quick rise in CSCC followed by a quick decrease in CSCC and is referred to as "quick recovery pattern." Three consecutive test-day records of CSCC had to be low, high, and low again (Figure 1). Pattern 2, referred to as "slow recovery pattern," described a slower increase in CSCC, but still with recovery, i.e., low, higher, high, lower, and low again (Figure 1). Pattern 3 had no restrictions on CSCC on the second and fourth test-day records, but the first one had to be low, the third one had to be high, and the fifth one had to be low again. There is overlap between patterns 2 and 3 , because of equal restrictions for the first, third, and fifth test day. Pattern 4 captured a longer increased SCC; i.e., low CSCC followed by four high CSCC, so no recovery took place within four test-day recordings. Pattern 4 is referred to as "no recovery pattern" (Figure 1). To compare these patterns with the lactation average of SCC, the fifth trait was a binary parameter that indicated whether the lactation average of SCC was higher or lower than 200,000 cells $/ \mathrm{mL}$ (scored as 1 or 0 , respectively) (SCC200).

Upper and lower thresholds for SCC were set based on findings in literature. Healthy and recovered cows were assumed to have less than 200,000 somatic cells/ $\mathrm{mL}$ (Dohoo and Leslie, 1991; Smith et al., 2001). Infected cows were assumed to produce more than 500,000 cell $\mathrm{s} / \mathrm{ml}$ (Lam et al., 1997). These thresholds for SCC are in accordance with a threshold of 100,000 cells/mL for low CSCC and a threshold of 400,000 cells/ $\mathrm{mL}$ for high CSCC since the average CSCC was 100,000 cells/mL. Although CSCC of zero represented the stan-

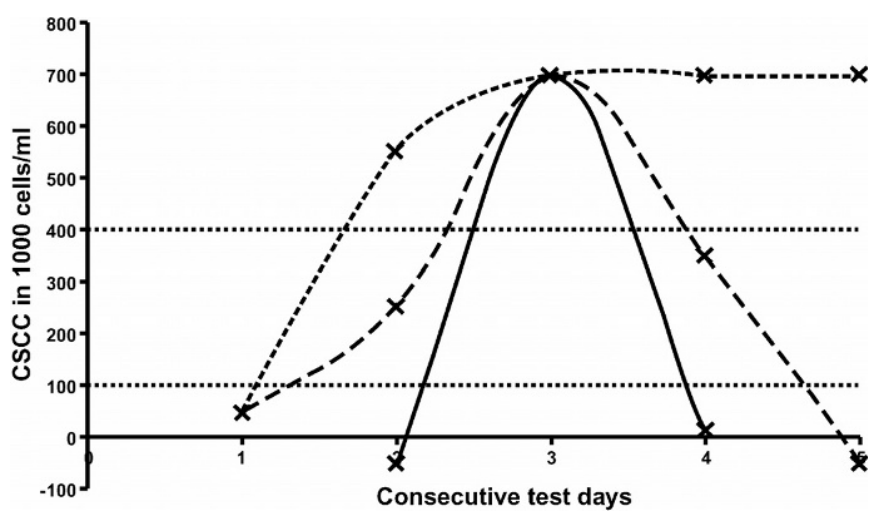

Figure 1. The solid line shows an example of a short, quick increase in SCC, relative to SCC for lactations without elevated SCC (CSCC), i.e., the "quick recovery pattern." The broken line shows an example of a slow increase in SCC, but with recovery within 5 consecutive test days, i.e., the "slow recovery pattern." The dotted line shows an example of a long increased SCC, without recovery within 5 consecutive test days, i.e., the "no recovery pattern." 
dard curve for lactations without CM and SCM, existing variation around this curve was taken into account when setting the thresholds for CSCC. The choice of thresholds, although objective, was arbitrary. Lower thresholds for CSCC of 50,000 and 150,000 cells/mL, and an upper threshold for CSCC of 650,000 cells $/ \mathrm{mL}$ were also evaluated.

The first criterion of all patterns of peaks in SCC is a low CSCC. However, to be able to identify cows with high CSCC directly after calving, the criteria for the definitions were set differently in the beginning of the lactation. At the end of the lactation, the criteria for the definitions were set differently as well, because cows might have been culled before they were recorded on the required number of test days included in the definition of the patterns of peaks in SCC. Therefore, in the beginning of the lactation, only the second half of the patterns of peaks in SCC was used, and at the end of the lactation the first half of the patterns of peaks in SCC was used. With three consecutive missing recordings on SCC, it was assumed that the cow was either culled or dried off.

Patterns of peaks in SCC were scored as categorical traits, so when a pattern was present in a lactation in 3 or 5 consecutive test-day recordings, it was registered as 1 , and otherwise as 0 . More than one pattern could be present in one lactation (Table 1).

\section{Odds Ratio, Sensitivity, Specificity, and Predictive Values}

Odds ratios (OR), sensitivities, and specificities were used to describe the associations between presence of patterns and incidence of pathogen-specific CM in lactations (Table 1). Odds ratio are measures of associations and indicate the change in risk. The sensitivity is the probability that a diseased animal (here defined as a lactation with occurrence of a pathogen-specific case of $\mathrm{CM}$ ) indeed will be classified as diseased using the test (here defined as a lactation with presence of any of the defined patterns), and the specificity is the probability that a nondiseased animal will be classified as nondiseased with the test (Noordhuizen et al., 1997). Specificity in this study is a relative specificity, since our golden standard is not without error because of variation between farmers in diagnostic criteria (Noordhuizen et al., 1997). The positive predictive value of a test is the probability that in a lactation with a given SCC pattern a case of $\mathrm{CM}$ with a given pathogen is diagnosed by the farmer. The negative predictive value is the probability that a case of $\mathrm{CM}$ with a given pathogen is not diagnosed in a lactation without a given SCC pattern. Contingency tables are fully filled, indicating that there are also lactations scored with a case of CM but without the presence of any of the patterns and vice versa, i.e., lactations without a case of CM, but with presence of a pattern.

The probabilities for occurrence of pathogen-specific CM in lactations with the presence of a SCC pattern were calculated with single-trait regressions and so were the probabilities for presence of a SCC pattern in lactations with occurrence of pathogen-specific CM. Both single-trait regressions were applied on two datasets, one including all available lactations $(n=24,012)$ (dataset 1), and one including only the lactations with CM $(\mathrm{n}=3393)$ (dataset 2). These datasets distinguish between probabilities of classifying a diseased cow out of all cows (dataset 1), and to identify the involved pathogen in cows with CM (dataset 2).

The effect of occurrence of pathogen-specific CM on the presence of one of the patterns was also investigated with a multivariate regression. Only one pathogen can occur in a lactation, and, therefore, pathogen-specific cases of $\mathrm{CM}$ are fully independent. Odds ratios, therefore, indicate probabilities on occurrence of specific pathogens versus no CM (dataset 1 ), or versus the group of remaining records (dataset 2).

Multivariate regression was also applied to investigate the effect of presence of any of the patterns in a lactation on occurrence of pathogen-specific CM. More than one pattern can be present in a lactation, so patterns are not independent. Odds ratios indicate the probability of the presence of a certain pattern versus no presence of patterns $1,2,3$, or 4 or SCC200, independent of the analyzed dataset. Fit of the models was evaluated based on the estimated deviance of the model.

\section{Statistical Analyses}

Statistical analyses were carried out to test whether OR differed from 1, using logistic regression in SAS [PROC GENMOD; (SAS/STAT, 2001)]. For investigating the effect of occurrence of pathogen-specific CM on presence of patterns, the analyses were done separately for each pattern (1, 2, 3, and 4), and for SCC200, with this general model:

$$
\begin{gathered}
\operatorname{Logit}(\mathrm{SCC} \text { pattern } \mathrm{j})=\alpha+\beta_{1} \mathrm{X}_{1}+\beta_{2} \mathrm{X}_{2}+\ldots \\
+\beta_{\mathrm{k}} \mathrm{X}_{\mathrm{k}}+\mathrm{e}_{\mathrm{jk}}
\end{gathered}
$$

where the outcome variable is a binary indicator variable $(0 / 1)$ for any of the patterns, with $\mathrm{j}=0 . .5$ (pattern 1 to 4 , or SCC200), $\alpha=$ intercept, and $\mathrm{e}=$ residual random error. The modeled probability was presence of a pattern and included regression coefficients were pathogen-specific $\mathrm{CM}\left(\beta_{1-8}\right)$, parity $\left(\beta_{9}\right)$, and the fraction of HF genes $\left(\beta_{10}\right)$. Eight classes for pathogen-specific $\mathrm{CM}$ were defined, i.e., seven classes for defined patho- 
gens, and one group of remaining records. Pathogenspecific CM was recorded as a binary trait (0/1).

For investigating the effect of presence of patterns on occurrence of pathogen-specific CM, the analyses were done separately for each pathogen, with this general model:

$$
\begin{aligned}
\operatorname{Logit}\left(\mathrm{CM}_{\mathrm{j}}\right) & =\alpha+\beta_{1} \mathrm{X}_{1}+\beta_{2} \mathrm{X}_{2}+\ldots \\
& +\beta_{\mathrm{k}} \mathrm{X}_{\mathrm{k}}+\mathrm{e}_{\mathrm{jk}}
\end{aligned}
$$

where the outcome variable is a binary indicator variable $(0 / 1)$ for pathogen-specific cases of $\mathrm{CM}$, with $\mathrm{j}=$ $0 \ldots 8, \alpha=$ intercept, and $\mathrm{e}=$ residual random error. The modeled probability was occurrence of pathogenspecific CM, and regression coefficients were estimated for the SCC patterns $\left(\beta_{1-4}\right), \operatorname{SCC} 200\left(\beta_{5}\right)$, parity $\left(\beta_{6}\right)$, and the fraction of $\mathrm{HF}$ genes $\left(\beta_{7}\right)$.

Parity had two classes, distinguishing between heifers and multiparous cows, and five classes of fractions of $\mathrm{HF}$ genes were defined $(0,1 / 4, \ldots, 4 / 4)$. Herd was included as a repeated variable (274 classes).

\section{RESULTS}

\section{Effect of Parity and Holstein \% on Patterns}

When all lactations were analyzed, incidence of patterns of peaks in SCC was lower in heifers than in multiparous cows $(P<0.05)$. When only the lactations with CM were analyzed, the "no recovery pattern" was significantly $(P<0.05)$ less present in heifers compared with multiparous cows. No significant associations were estimated for the other patterns.

Long increased SCC was more frequent in cows with 26 to $75 \% \mathrm{HF}$, compared with cows with 76 to $100 \%$ HF. Furthermore, more lactations of cows with $\leq 75 \%$ HF had averages of SCC of $>200,000$ cells $/ \mathrm{mL}$, than of cows with 76 to $100 \%$ HF. Similar results were found in dataset 2; i.e., lactations of cows with 26 to $50 \%$ HF showed more often high averages of SCC $(>200,000$ cells $/ \mathrm{mL}$ ), than lactations of cows with 76 to $100 \% \mathrm{HF}$.

\section{Single-Trait Analyses for Associations Between Pattern and Pathogen}

All calculated OR in dataset 1 are above 1, indicating that a diseased cow can be classified out of all cows by presence of SCC patterns (Table 2). Odds ratios for SCC200 were highest for cases of CM associated with Staph. aureus, Strep. dysgalactiae, Strep. uberis, and the group of remaining records. Cases of CM associated with CNS or streptococci other than Strep. dysgalactiae and Strep. uberis showed highest OR for the "no recovery pattern." Chances on the presence of the "quick recovery pattern" were high in lactations with clinical
$E$. coli mastitis compared with the presence of another SCC pattern. No single unambiguous SCC pattern was present for culture-negative samples.

For all pathogens, sensitivities for SCC200 were higher than the sensitivities for any pattern of peaks in SCC (Table 2). Pattern 3 was always more sensitive than the other patterns, independent of the pathogen, and the "slow recovery pattern" showed lowest sensitivity for all pathogens, when analyzing dataset 1 . Specificities were always lowest for SCC200 and highest for the "slow recovery pattern." However, despite the high specificity of the "slow recovery pattern," this is probably not the best trait to detect lactations with pathogenspecific CM because of the low sensitivity.

The negative predictive values were high, especially when analyzing all lactations, compared with analyzing only lactations with CM (Table 2). This indicated that in at least $95 \%$ of all lactations, absence of pathogenspecific CM was correctly predicted by absence of any of the defined patterns of peaks in SCC. However, probabilities that the presence of a pattern correctly predicted occurrence of pathogen-specific CM were low ( $\leq$ $17 \%$ ) when analyzing dataset 1 . When analyzing dataset 2 , positive predictive values were higher than with dataset 1. In lactations with CM and with presence of the "no recovery pattern" the predictive value for Staph. aureus is $19 \%$, whereas this is only $9 \%$ for $E$. coli. On the other hand, the "quick recovery pattern" predicted $22 \%$ of the cases of $E$. coli mastitis in lactations with CM, and only $8 \%$ of the cases of Staph. aureus mastitis.

\section{Multivariate Analyses for Effect of Pathogens on Pattern}

Slightly higher OR were calculated with multivariate analyses (Tables 3 and 4), compared with single-trait analyses (Table 2), especially when analyzing dataset 1 , and only to some extent when analyzing dataset 2 .

Clinical $E$. coli mastitis was significantly associated with an increased risk on presence of a "quick recovery pattern" (OR = 3.14) (Table 3). Clinical Staph. aureus or CNS mastitis was associated with increased risk on presence of a "no recovery pattern," with OR of above 6. Clinical Staph. aureus or CNS mastitis was also associated with increased odds of a "slow recovery pattern," compared with lactations with presence of a "slow recovery pattern," but without a case of $\mathrm{CM}(\mathrm{OR}=3.71$ and 3.75 , respectively).

In lactations with $\mathrm{CM}$, the odds of "quick recovery pattern" (versus none of the SCC patterns being present) were roughly $50 \%$ when Staph. aureus or CNS were isolated ( $\mathrm{OR}=0.60$ and 0.47 , respectively) (Table 4). Probabilities of observing cases of CM associated with $E$. coli, Strep. dysgalactiae, or culture-negative 
Table 2. Calculated odds ratio (OR) for the effect of patterns in $\mathrm{SCC}^{1}$ on pathogen-specific clinical mastitis $(\mathrm{CM})$. Sensitivity (SE) and specificity (SP) indicating that lactations with or without pathogen-specific CM are detected or not detected by a certain pattern respectively. Predictive values, positive and negative (PV+, PV-), to indicate the probability that a SCC pattern correctly predicts presence or absence of pathogenspecific CM. Analyses are performed for all available lactations and only the lactations with CM, separately.

\begin{tabular}{|c|c|c|c|c|c|c|c|c|c|c|}
\hline & \multicolumn{5}{|c|}{ All lactations } & \multicolumn{5}{|c|}{ Only lactations with CM } \\
\hline & OR & $\mathrm{SE}$ & SP & $\mathrm{PV}+$ & $\mathrm{PV}-$ & OR & SE & SP & $\mathrm{PV}+$ & PV- \\
\hline \multicolumn{11}{|c|}{ Staphylococcus aureus } \\
\hline Pattern 1 & 1.36 & 0.14 & 0.89 & 0.02 & 0.98 & 0.61 & 0.14 & 0.78 & 0.08 & 0.87 \\
\hline Pattern 2 & 3.46 & 0.05 & 0.99 & 0.05 & 0.98 & 1.84 & 0.05 & 0.97 & 0.19 & 0.89 \\
\hline Pattern 3 & 1.96 & 0.21 & 0.88 & 0.03 & 0.99 & 0.87 & 0.21 & 0.76 & 0.11 & 0.88 \\
\hline Pattern 4 & 5.29 & 0.13 & 0.97 & 0.07 & 0.99 & 1.96 & 0.13 & 0.93 & 0.19 & 0.89 \\
\hline SCC200 & 7.76 & 0.74 & 0.73 & 0.04 & 0.99 & 2.66 & 0.74 & 0.48 & 0.16 & 0.93 \\
\hline \multicolumn{11}{|c|}{ Coagulase-negative staphylococci } \\
\hline Pattern 1 & 1.09 & 0.12 & 0.89 & 0.01 & 0.99 & 0.50 & 0.12 & 0.79 & 0.02 & 0.96 \\
\hline Pattern 2 & 3.14 & 0.04 & 0.99 & 0.01 & 0.99 & 1.60 & 0.04 & 0.97 & 0.05 & 0.97 \\
\hline Pattern 3 & 1.47 & 0.17 & 0.88 & 0.01 & 0.99 & 0.66 & 0.17 & 0.76 & 0.03 & 0.96 \\
\hline Pattern 4 & 4.15 & 0.11 & 0.97 & 0.02 & 0.99 & 1.48 & 0.11 & 0.92 & 0.05 & 0.97 \\
\hline SCC200 & 1.98 & 0.43 & 0.73 & 0.01 & 0.99 & 0.62 & 0.43 & 0.45 & 0.03 & 0.96 \\
\hline \multicolumn{11}{|c|}{ Escherichia coli } \\
\hline Pattern 1 & 2.78 & 0.25 & 0.89 & 0.06 & 0.98 & 1.33 & 0.25 & 0.80 & 0.22 & 0.83 \\
\hline Pattern 2 & 2.00 & 0.03 & 0.99 & 0.05 & 0.97 & 0.98 & 0.03 & 0.97 & 0.18 & 0.82 \\
\hline Pattern 3 & 2.47 & 0.25 & 0.88 & 0.05 & 0.98 & 1.11 & 0.25 & 0.77 & 0.23 & 0.82 \\
\hline Pattern 4 & 1.38 & 0.04 & 0.97 & 0.04 & 0.97 & 0.43 & 0.04 & 0.91 & 0.09 & 0.81 \\
\hline SCC200 & 1.98 & 0.42 & 0.73 & 0.04 & 0.98 & 0.56 & 0.42 & 0.43 & 0.14 & 0.77 \\
\hline \multicolumn{11}{|c|}{ Streptococcus dysgalactiae } \\
\hline Pattern 1 & 2.45 & 0.23 & 0.89 & 0.02 & 0.99 & 1.15 & 0.23 & 0.79 & 0.07 & 0.94 \\
\hline Pattern 2 & 2.32 & 0.03 & 0.99 & 0.02 & 0.99 & 1.17 & 0.03 & 0.97 & 0.07 & 0.94 \\
\hline Pattern 3 & 2.58 & 0.26 & 0.88 & 0.02 & 0.99 & 1.18 & 0.26 & 0.77 & 0.07 & 0.94 \\
\hline Pattern 4 & 1.57 & 0.05 & 0.97 & 0.01 & 0.99 & 0.53 & 0.05 & 0.92 & 0.04 & 0.93 \\
\hline SCC200 & 4.43 & 0.62 & 0.73 & 0.02 & 0.99 & 1.43 & 0.62 & 0.46 & 0.07 & 0.95 \\
\hline \multicolumn{11}{|c|}{ Streptococcus uberis } \\
\hline Pattern 1 & 2.28 & 0.22 & 0.89 & 0.01 & 0.99 & 1.07 & 0.22 & 0.79 & 0.05 & 0.95 \\
\hline Pattern 2 & 2.76 & 0.04 & 0.99 & 0.02 & 0.99 & 1.40 & 0.04 & 0.97 & 0.06 & 0.95 \\
\hline Pattern 3 & 2.33 & 0.25 & 0.88 & 0.01 & 0.99 & 1.06 & 0.25 & 0.76 & 0.05 & 0.95 \\
\hline Pattern 4 & 3.47 & 0.09 & 0.97 & 0.02 & 0.99 & 1.23 & 0.09 & 0.92 & 0.06 & 0.95 \\
\hline SCC200 & 3.96 & 0.59 & 0.73 & 0.01 & 0.99 & 1.27 & 0.59 & 0.46 & 0.05 & 0.96 \\
\hline \multicolumn{11}{|c|}{ Other streptococci } \\
\hline Pattern 1 & 2.61 & 0.24 & 0.89 & 0.02 & 0.99 & 1.23 & 0.24 & 0.79 & 0.06 & 0.95 \\
\hline Pattern 2 & 1.15 & 0.02 & 0.99 & 0.01 & 0.99 & 0.56 & 0.02 & 0.97 & 0.03 & 0.94 \\
\hline Pattern 3 & 2.74 & 0.28 & 0.88 & 0.02 & 0.99 & 1.25 & 0.28 & 0.77 & 0.06 & 0.95 \\
\hline Pattern 4 & 3.37 & 0.04 & 0.97 & 0.02 & 0.99 & 1.19 & 0.04 & 0.92 & 0.06 & 0.95 \\
\hline SCC200 & 3.00 & 0.53 & 0.73 & 0.01 & 0.99 & 0.95 & 0.53 & 0.46 & 0.05 & 0.94 \\
\hline \multicolumn{11}{|c|}{ Culture-negative samples } \\
\hline Pattern 1 & 1.77 & 0.18 & 0.89 & 0.03 & 0.98 & 0.79 & 0.18 & 0.79 & 0.12 & 0.85 \\
\hline Pattern 2 & 1.30 & 0.02 & 0.99 & 0.03 & 0.98 & 0.61 & 0.02 & 0.97 & 0.10 & 0.85 \\
\hline Pattern 3 & 1.82 & 0.20 & 0.88 & 0.03 & 0.98 & 0.79 & 0.20 & 0.76 & 0.12 & 0.85 \\
\hline Pattern 4 & 1.25 & 0.04 & 0.97 & 0.03 & 0.98 & 0.40 & 0.04 & 0.91 & 0.07 & 0.85 \\
\hline SCC200 & 1.45 & 0.35 & 0.73 & 0.03 & 0.98 & 0.41 & 0.35 & 0.43 & 0.09 & 0.79 \\
\hline \multicolumn{11}{|c|}{ Other pathogens } \\
\hline Pattern 1 & 2.41 & 0.22 & 0.89 & 0.10 & 0.96 & 1.11 & 0.22 & 0.80 & 0.37 & 0.65 \\
\hline Pattern 2 & 1.79 & 0.02 & 0.99 & 0.09 & 0.95 & 0.81 & 0.02 & 0.97 & 0.31 & 0.64 \\
\hline Pattern 3 & 2.42 & 0.24 & 0.88 & 0.10 & 0.96 & 1.06 & 0.24 & 0.77 & 0.36 & 0.65 \\
\hline Pattern 4 & 4.08 & 0.10 & 0.97 & 0.17 & 0.95 & 1.48 & 0.10 & 0.93 & 0.44 & 0.65 \\
\hline SCC200 & 4.44 & 0.61 & 0.74 & 0.11 & 0.97 & 1.50 & 0.61 & 0.49 & 0.40 & 0.69 \\
\hline
\end{tabular}

${ }^{1}$ Pattern 1: low-high-low; pattern 2: low-higher-high-lower-low; pattern 3: low-no restrictions-high-no restrictions-low; pattern 4: low-high-high-high-high; SCC200: lactation average SCC of higher than 200,000 cells $/ \mathrm{ml}$

samples were low compared with lactations with presence of a "no recovery pattern" and a case of CM associated with the group of remaining records.

High OR were estimated for SCC200 when analyzing dataset 1 (Table 3), indicating higher chances of finding high lactation averages of SCC in lactations with patho- gen-specific CM than in lactations without CM. Among the lactations with CM, Staph. aureus was the only pathogen that was associated with an increased odds of SCC200, compared with the group of remaining records (Table 4). Most other pathogens were associated with a decreased odds of SCC200, compared with the group 
Table 3. The odds ratio (OR) for the effect of pathogen-specific clinical mastitis (CM) on four patterns of peaks in $\mathrm{SCC}^{1}$ and lactation average SCC of higher than 200,000 cells $/ \mathrm{mL}$, separately, when analyzing all available lactations.

\begin{tabular}{llllll}
\hline & Pattern 1 & Pattern 2 & Pattern 3 & Pattern 4 & SCC200 \\
\hline Staphylococcus aureus & $1.63^{*}$ & $3.71^{*}$ & $2.31^{*}$ & $6.24^{*}$ & $9.31^{*}$ \\
Coagulase-negative staphylococci & 1.34 & $3.75^{*}$ & $1.82^{*}$ & $6.31^{*}$ & $2.94^{*}$ \\
Escherichia coli & $3.14^{*}$ & $2.14^{*}$ & $2.79^{*}$ & $1.74^{*}$ & $2.33^{*}$ \\
Streptococcus dysgalactiae & $2.90^{*}$ & $2.62^{*}$ & $3.06^{*}$ & $2.04^{*}$ & $5.41^{*}$ \\
Streptococcus uberis & $2.67^{*}$ & $3.08^{*}$ & $2.70^{*}$ & $4.09^{*}$ & $4.86^{*}$ \\
Other streptococci & $3.02^{*}$ & 1.29 & $3.17^{*}$ & $4.19^{*}$ & $3.68^{*}$ \\
Culture-negative samples & $2.15^{*}$ & 1.44 & $2.19^{*}$ & $1.72^{*}$ & $2.00^{*}$ \\
Other pathogens & $2.73^{*}$ & $1.92^{*}$ & $2.70^{*}$ & $4.49^{*}$ & $4.97^{*}$ \\
\hline
\end{tabular}

${ }^{1}$ Pattern 1: low-high-low; pattern 2: low-higher-high-lower-low; pattern 3: low-no restrictions-high-no restrictions-low; pattern 4: low-high-high-high-high; SCC200: lactation average SCC of higher than 200,000 cells $/ \mathrm{ml}$.

*Significantly different from 1 , with $P<0.05$.

of remaining records, although Strep. dysgalactiae and Strep. uberis differed not significantly from 1.

Changing the threshold values had no severe impact on the associations between occurrence of pathogenspecific $\mathrm{CM}$ and presence of patterns. Interpretations of OR were similar, independent of the threshold values.

\section{Multivariate Analyses for Effect of Patterns on Pathogen}

With multivariate analyses, lower OR were calculated (Table 5) compared with single-trait analyses (Table 2), especially when analyzing dataset 1 . Different combinations of patterns included in the model resulted in different estimates for OR, and possibilities to elucidate specific mastitis-causing pathogens differed as well. For Staph. aureus, a better fit was found for the model including all patterns versus separate models with each pattern. This indicated that for Staph. aureus a model can be defined including a combination of the patterns, resulting in an optimal fit of the model (results not shown). For other pathogens, including more patterns in the model, did not improve the fit of the model, so a model with only one pattern is preferred (results not shown).

All patterns except the "slow recovery pattern" were significantly associated with increased risk on overall $\mathrm{CM}$, whereas the "slow recovery pattern" was associated with a decreased risk on overall CM (Table 5). The "no recovery pattern" and SCC200 were associated with increased odds of clinical Staph. aureus mastitis, but the "quick recovery pattern" was associated with decreased odds of Staph. aureus. This implied that presence of a long increased SCC, without recovery within 4 consecutive test days, was rather common in lactations with clinical Staph. aureus mastitis, as well as the presence of a high lactation average of SCC, but presence of the "quick recovery pattern" was not so common. When analyzing dataset 1, SCC200 was associated with an increased risk on clinical CNS mastitis, whereas, when analyzing only lactations with CM (dataset 2), SCC200 was associated with a decreased risk on CNS. This implied a higher risk on occurrence of CNS in lactations with high averaged SCC. Among lactations with CM, CNS mastitis did not occur more often in lactations with high lactation average SCC. The "quick

Table 4. The odds ratio (OR) for the effect of pathogen-specific clinical mastitis (CM) on four patterns of peaks in $\mathrm{SCC}^{1}$ and lactation average $\mathrm{SCC}$ of higher than 200,000 cells/mL, separately, when analyzing only lactations with CM.

\begin{tabular}{llllll}
\hline & Pattern 1 & Pattern 2 & Pattern 3 & Pattern 4 & SCC200 \\
\hline Staphylococcus aureus & $0.60^{*}$ & $1.91^{*}$ & 0.85 & 1.39 & $1.94^{*}$ \\
Coagulase-negative staphylococci & $0.47^{*}$ & 1.80 & 0.64 & 1.27 & $0.56^{*}$ \\
Escherichia coli & 1.18 & 1.14 & 1.05 & $0.37^{*}$ & $0.47^{*}$ \\
Streptococcus dysgalactiae & 1.06 & 1.33 & 1.12 & $0.45^{*}$ & 1.06 \\
Streptococcus uberis & 0.98 & 1.58 & 1.00 & 0.96 & 0.96 \\
Other streptococci & 1.13 & 0.67 & 1.18 & 0.95 & $0.75^{*}$ \\
Culture-negative samples & 0.77 & 0.74 & 0.79 & $0.38^{*}$ & $0.39^{*}$ \\
\hline
\end{tabular}

${ }^{1}$ Pattern 1: low-high-low; pattern 2: low-higher-high-lower-low; pattern 3: low-no restrictions-high-no restrictions-low; pattern 4: low-high-high-high-high; SCC200: lactation average SCC of higher than 200,000 cells $/ \mathrm{ml}$.

*Significantly different from 1 , with $P<0.05$. 
Table 5. The odds ratio (OR) and the $95 \%$ confidence interval for the effect of patterns in $\mathrm{SCC}^{1}$ on pathogenspecific clinical mastitis (CM), when analyzing all available lactations or only the lactations with CM, separately.

\begin{tabular}{|c|c|c|c|c|c|c|}
\hline & \multicolumn{3}{|c|}{ All lactations } & \multicolumn{3}{|c|}{ Only lactations with CM } \\
\hline & $\mathrm{OR}^{2}$ & \multicolumn{2}{|c|}{ 95\% Confidence interval } & $\mathrm{OR}^{2}$ & \multicolumn{2}{|c|}{ 95\% Confidence interval } \\
\hline \multicolumn{7}{|c|}{ Overall clinical mastitis } \\
\hline Pattern 1 & 1.37 & 1.20 & 1.56 & & & \\
\hline Pattern 2 & 0.74 & 0.56 & 0.97 & & & \\
\hline Pattern 3 & 1.47 & 1.29 & 1.68 & & & \\
\hline Pattern 4 & 1.91 & 1.63 & 2.23 & & & \\
\hline SCC200 & 3.17 & 2.89 & 3.48 & & & \\
\hline \multicolumn{7}{|c|}{ Staphylococcus aureus } \\
\hline Pattern 1 & 0.70 & 0.51 & 0.95 & 0.57 & 0.42 & 0.77 \\
\hline Pattern 2 & 1.10 & 0.63 & 1.94 & 1.58 & 0.88 & 2.82 \\
\hline Pattern 3 & 1.12 & 0.81 & 1.54 & 0.85 & 0.62 & 1.16 \\
\hline Pattern 4 & 1.77 & 1.28 & 2.45 & 1.14 & 0.80 & 1.62 \\
\hline SCC200 & 7.44 & 5.68 & 9.73 & 2.96 & 2.25 & 3.91 \\
\hline \multicolumn{7}{|c|}{ Coagulase-negative staphylococci } \\
\hline Pattern 1 & 0.83 & 0.47 & 1.44 & 0.62 & 0.36 & 1.06 \\
\hline Pattern 2 & 1.38 & 0.47 & 4.04 & 1.85 & 0.65 & 5.28 \\
\hline Pattern 3 & 1.20 & 0.61 & 2.36 & 0.84 & 0.45 & 1.55 \\
\hline Pattern 4 & 2.89 & 1.51 & 5.57 & 1.88 & 0.99 & 3.56 \\
\hline SCC200 & 1.79 & 1.15 & 2.82 & 0.65 & 0.43 & 1.00 \\
\hline \multicolumn{7}{|c|}{ Escherichia coli } \\
\hline Pattern 1 & 1.96 & 1.54 & 2.49 & 1.48 & 1.17 & 1.86 \\
\hline Pattern 2 & 1.16 & 0.64 & 2.10 & 1.34 & 0.74 & 2.42 \\
\hline Pattern 3 & 1.35 & 1.02 & 1.77 & 0.97 & 0.75 & 1.27 \\
\hline Pattern 4 & 1.00 & 0.64 & 1.55 & 0.58 & 0.38 & 0.89 \\
\hline SCC200 & 1.45 & 1.20 & 1.74 & 0.53 & 0.44 & 0.64 \\
\hline \multicolumn{7}{|c|}{ Streptococcus dysgalactiae } \\
\hline Pattern 1 & 1.23 & 0.78 & 1.94 & 1.00 & 0.67 & 1.49 \\
\hline Pattern 2 & 1.00 & 0.45 & 2.21 & 1.07 & 0.48 & 2.39 \\
\hline Pattern 3 & 1.35 & 0.88 & 2.06 & 1.02 & 0.69 & 1.50 \\
\hline Pattern 4 & 0.72 & 0.38 & 1.38 & 0.46 & 0.24 & 0.87 \\
\hline SCC200 & 4.14 & 3.01 & 5.69 & 1.56 & 1.17 & 2.07 \\
\hline \multicolumn{7}{|c|}{ Streptococcus uberis } \\
\hline Pattern 1 & 1.34 & 0.80 & 2.23 & 1.05 & 0.65 & 1.68 \\
\hline Pattern 2 & 1.09 & 0.42 & 2.84 & 1.36 & 0.56 & 3.30 \\
\hline Pattern 3 & 1.25 & 0.74 & 2.09 & 0.94 & 0.59 & 1.51 \\
\hline Pattern 4 & 1.63 & 0.89 & 2.96 & 1.08 & 0.61 & 1.93 \\
\hline SCC200 & 3.16 & 2.16 & 4.62 & 1.22 & 0.84 & 1.77 \\
\hline \multicolumn{7}{|c|}{ Other streptococci } \\
\hline Pattern 1 & 1.34 & 0.84 & 2.13 & 1.05 & 0.68 & 1.60 \\
\hline Pattern 2 & 0.33 & 0.09 & 1.15 & 0.40 & 0.12 & 1.42 \\
\hline Pattern 3 & 1.86 & 1.24 & 2.79 & 1.38 & 0.95 & 1.99 \\
\hline Pattern 4 & 2.26 & 1.25 & 4.08 & 1.42 & 0.78 & 2.57 \\
\hline SCC200 & 2.12 & 1.53 & 2.94 & 0.86 & 0.63 & 1.16 \\
\hline \multicolumn{7}{|c|}{ Culture-negative samples } \\
\hline Pattern 1 & 1.31 & 0.99 & 1.73 & 0.94 & 0.71 & 1.23 \\
\hline Pattern 2 & 0.80 & 0.40 & 1.61 & 0.85 & 0.40 & 1.79 \\
\hline Pattern 3 & 1.44 & 1.06 & 1.96 & 0.98 & 0.72 & 1.34 \\
\hline Pattern 4 & 1.08 & 0.67 & 1.72 & 0.67 & 0.41 & 1.10 \\
\hline SCC200 & 1.32 & 1.05 & 1.65 & 0.46 & 0.37 & 0.58 \\
\hline \multicolumn{7}{|c|}{ Other pathogens } \\
\hline Pattern 1 & 1.31 & 1.07 & 1.61 & 1.05 & 0.84 & 1.30 \\
\hline Pattern 2 & 0.57 & 0.36 & 0.89 & 0.70 & 0.42 & 1.17 \\
\hline Pattern 3 & 1.37 & 1.13 & 1.66 & 1.01 & 0.83 & 1.24 \\
\hline Pattern 4 & 2.00 & 1.62 & 2.47 & 1.28 & 1.00 & 1.65 \\
\hline SCC200 & 3.53 & 3.06 & 4.07 & 1.42 & 1.22 & 1.66 \\
\hline
\end{tabular}

${ }^{1}$ Pattern 1: low-high-low; pattern 2: low-higher-high-lower-low; pattern 3: low-no restrictions-high-no restrictions-low; pattern 4: low-high-high-high-high; SCC200: lactation average SCC of higher or lower than 200,000 cells $/ \mathrm{mL}$.

${ }^{2}$ Odds ratio for having a lactation with the occurrence of a certain pattern compared with lactations with the occurrence of any other pattern, not described by pattern 1, 2, 3, or 4 or SCC200. 
recovery pattern" was significantly more often present in lactations with clinical $E$. coli mastitis, compared with peaks in SCC not described by pattern $1,2,3$, or 4 or SCC200. For cases of CM associated with one of the streptococci or a culture-negative sample, no clear associations with a SCC pattern in particular were found.

\section{DISCUSSION}

\section{Effect of Parity and Percentage HF on Presence of Patterns}

Lactation average SCC increases with increasing parity (Blackburn, 1966; Lindström et al., 1981). In the current study, SCC adjusted for SCC of healthy cows (CSCC) was used, which was also corrected for lactation stage and parity effect. Still, the number of peaks in CSCC increased with increasing parity. This was especially true for the "no recovery pattern," where $61 \%$ of all lactations with the presence of this pattern were from fourth- or higher parity cows, whereas 35,44 , and $36 \%$ of all lactations with the presence of patterns 1 , 2 , and 3 , respectively, were from fourth- or higher parity cows. The number of cases of CM also increased with increasing parities (Detilleux et al., 1995; Martin et al., 2002). In the current study, CM was recorded in 9.3, $13.3,16.3$, and $18.6 \%$ of all lactations from cows in parities $1,2,3$, and $\geq 4$, respectively. This might explain the higher number of peaks for older cows, compared with cows of first, second, or third parity.

Patterns of peaks in SCC are more often present in cows with relatively low percentages of HF. This might be (partly) explained by the higher incidences of cases of $\mathrm{CM}$ in cows with $\leq 75 \% \mathrm{HF}$, compared with cows with $>76 \% \mathrm{HF}$. This distribution has been presented before by De Haas et al. (2002a).

\section{Biological Interpretation of Patterns}

Intramammary infections with Staph. aureus are often characterized by a long duration and high SCC (Sears et al., 1990; Daley et al., 1991), although a wavelike pattern of increased SCC may be present (Daley et al., 1991). Cases of clinical Staph. aureus mastitis occurred more frequently in later lactation (Vaarst and Enevoldsen, 1997) and may therefore be more easily detected using the patterns. As expected, Staph. aureus was more often associated with the "no recovery pattern," and less often with the "quick recovery pattern."

Phenotypic associations in the current study also showed that clinical $E$. coli mastitis is associated with short peaks in SCC. Escherichia coli infections are typically acute cases (Vaarst and Enevoldsen, 1997), which agrees with the strong association found between the "quick recovery pattern" SCC and clinical E. coli mastitis in the current study. These results are confirmed by studies that used either induced cases or naturally occurring cases of CM. The effect of naturally occurring cases of clinical $E$. coli mastitis on the curve of SCC during lactation has been described using the same dataset (De Haas et al., 2002a). Before a case of clinical $E$. coli mastitis, SCC was close to the SCC level of lactations without CM and SCM, and after the case SCC came down to a level that was only slightly higher than the preinfection level. From experiments inducing $E$. coli, it was shown that SCC peaks $2 \mathrm{~d}$ after inoculation, and preinfection SCC values returned within 3 to 4 wk after challenge (Lohuis et al., 1990; Erskine et al., 1992; Kremer et al., 1993; Pyörälä et al., 1994). In contrast, within $24 \mathrm{~h}$ after inoculation with Staph. aureus, SCC increased and remained high for at least 48 d (Shoshani et al., 2000). Culture-negative CM showed strong similarities with clinical coliform mastitis (Vaarst and Enevoldsen, 1997), and associations between patterns and culture-negative $\mathrm{CM}$ in the current study were indeed similar to those with $E$. coli mastitis.

Based on the results in the current study, clinical Strep. dysgalactiae mastitis was not strongly associated with the presence of one pattern in particular, because OR were around 1, which agrees with the specific characteristics of Strep. dysgalactiae reported by Vaarst and Enevoldsen (1997). Leigh (1999) concluded that clinical Strep. uberis mastitis can be associated with longer increased SCC, which was also established in the current study when analyzing dataset 1 .

When interpreting the patterns of peaks in SCC, it should be taken into account that the pattern after the rise in SCC is affected by the type of therapy of the cow. However, because all cows with CM were treated, this effect is present for each pattern. In practice, cows are treated as well; hence, the data used in this study correspond with data that are available to farmers. Responses to the therapy might differ per cow, and with the data analyzed in this study it is impossible to specify whether cure occurs spontaneous or as a result of therapy, but that is also unknown in practical situations. To diagnose individual cows by using the SCC patterns might not be the best method, because of the time needed to complete a pattern. For individual cases, bacteriology of milk samples will provide quicker and more accurate results. However, when analyzing these SCC patterns at herd level, a predominant pathogen picture might occur. This can help with introducing pathogenspecific mastitis control programs, consisting of adequate guidelines to control IMI with both contagious and environmental pathogens. 


\section{Comparison of Patterns 1 to 4 with SCC200}

Although it is not exactly the same trait as the lactation average of SCC, SCC200 was defined to be able to make the comparison with average lactation values for SCC, which is currently used to monitor udder health. The major difference is that lactation average SCC gives as much weight to a reduction of 150,000 to 50,000 cells $/ \mathrm{mL}$, as from 900,000 to 800,000 cells $/ \mathrm{mL}$, whereas SCC200 only distinguishes between high versus low lactation averages of SCC. Therefore, associations between lactation average SCC and pathogen-specific CM might differ from those found for SCC200. Heuven (1987) compared several SCC variables as predictors of bacteriological status and concluded that cows with high deviations from the typical curve of SCC during lactation were more likely to be treated for CM. Still, lactation average SCC was a more accurate predictor of pathogens than a single SCC measure on bacteriological sample day (Heuven, 1987). Based on comparison of the positive predictive values, occurrence of pathogenspecific CM was equally or even more correctly predicted by presence of one of the SCC patterns than by presence of SCC200. Lactations with presence of the "no recovery pattern" had more chance on occurrence of clinical Staph. aureus mastitis, compared with the base probability of Staph. aureus (2\%) (Table 1). Higher probabilities than the base probability were found for $E$. coli when the "quick recovery pattern" was present in a lactation. Lactations with CM and with presence of the "no recovery pattern" had high probabilities on clinical Staph. aureus or CNS mastitis, but low probabilities on $E$. coli or culture-negative CM. The opposite was true for lactations with presence of the "quick recovery pattern". The results support the hypothesis that a different definition of SCC can increase the predictive value of the bacteriological status of a cow, but a combination of several definitions of SCC might be necessary to capture the full scope of mastitis-causing pathogens. Patterns of peaks in SCC may be useful as basic tools for health management advice, as they do provide additional information on, for example, the incidence of (spontaneous or therapeutic) cure, in comparison with the information provided by lactation average SCC alone. Further analyses will be done on the distributions of the SCC patterns on farms and whether this is informative for pathogen-distribution on that farm. Genetic analyses will be carried out as well to establish whether decreased genetic susceptibility to mastitiscausing pathogens can be achieved by genetic selection on patterns of peaks in SCC.

\section{Further Optimization of Trait Definition}

Several improvements in the current analyses can be made that are expected to increase the detection of the SCC patterns or to increase the chance of finding an association between SCC patterns and CM. For example, noise in SCC test-day recordings might be removed from the data by correcting for fixed effects, such as herd-test-date, in the statistical model. Chances of finding a peak in SCC were also determined by the frequency of the test-day recordings. Recording an increased SCC on the test day depended on both the day of occurrence of cases of $\mathrm{CM}$ in relation to test-day recordings and the duration of increased SCC as a result of pathogen-specific CM. Using this additional information will mainly help to detect acute cases of CM, but not the chronic cases because SCC remains high for some time with a chronic case of CM. Therefore, chances of detecting such a high SCC are higher compared with detecting an increased SCC as a result of an acute case of CM since SCC rises quickly and is low before and after an acute case of CM.

\section{CONCLUSIONS}

The presence of patterns in a lactation is informative for the pathogen-specific incidence of CM. Patterns can distinguish between cases of pathogen-specific CM, and they predict the occurrence of pathogen-specific CM equally or even more accurately than SCC200. Lactations with CM and with presence of the "no recovery pattern" had high probabilities for clinical Staph. aureus or CNS mastitis but low probabilities for $E$. coli or culture-negative CM. The opposite was true for lactations with presence of the "quick recovery pattern". The presence of patterns of peaks in SCC can be partly explained by pathogen-specific mammary gland pathogenesis since pathogens may have typical characteristics.

\section{ACKNOWLEDGMENTS}

This research was supported by the Dutch Ministry of Agriculture. Financial support from NRS and Dairy Commodity Board is greatly appreciated. NRS is acknowledged for providing data on milk recordings. The authors thank Pim Brascamp, Ab Groen, and Gerben de Jong for their suggestions and useful comments on the manuscripts.

\section{REFERENCES}

Barkema, H. W., Y. H. Schukken, T. J. G. M. Lam, M. L. Beiboer, H. Wilmink, G. Benedictus, and A. Brand. 1998. Incidence of clinical mastitis in dairy herds grouped in three categories by bulk milk somatic cell counts. J. Dairy Sci. 81:411-419.

Blackburn, P. S. 1966. The variation in cell count of cow's milk throughout lactation and from one lactation to the next. J. Dairy Res. 33:193-198.

Daley, M. J., E. R. Oldham, T. J. Williams, and P. A. Coyle. 1991. Quantitative and qualitative properties of host polymorphonu- 
clear cells during experimentally induced Staphylococcus aureus mastitis in cows. Am. J. Vet. Res. 52:474-479.

De Haas, Y., H. W. Barkema, and R. F. Veerkamp. 2002a. The effect of pathogen-specific clinical mastitis on the lactation curve of somatic cell count. J. Dairy Sci. 85:1314-1323.

De Haas, Y., H. W. Barkema, and R. F. Veerkamp. 2002b. Genetic parameters of pathogen-specific incidence of clinical mastitis in dairy cows. Anim. Sci. 74:233-242.

Detilleux, J. C., M. E. Kehrli, Jr., A. E. Freeman, L. K. Fox, and D. H. Kelley. 1995. Mastitis of periparturient Holstein cattle: A phenotypic and genetic study. J. Dairy Sci. 78:2285-2293.

Dohoo, I. R., and K. E. Leslie. 1991. Evaluation of changes in somatic cell counts as indicators of new intramammary infections. Prev. Vet. Med. 10:225-237.

Erskine, R. J., R. C. Wilson, M. G. Riddell, J. W. Tyler, H. J. Spears, and B. S. Davis. 1992. Intramammary administration of gentamicin as treatment for experimentally induced Escherichia coli mastitis in cows. Am. J. Vet. Res. 53:375-381.

Gilmour, A. R., B. R. Cullis, S. J. Welham, and R. Thompson. 2002. AS-REML Reference Manual, NSW Agriculture, ORANGE, 2800, Australia.

Harmon, R. J., R. J. Eberhart, D. E. Jasper, B. E. Langlois, and R. A. Wilson. 1990. Microbiological procedures for the diagnosis of bovine udder infection. National Mastitis Council, Inc., Arlington, VA.

Heuven, H. C. M. 1987. Diagnostic and genetic analysis of mastitis field data. University of Wisconsin, Madison.

Kremer, W. D. J., E. N. Noordhuizen-Stassen, F. J. Grommers, A. Daemen, P. A. J. Henricks, A. Brand, and C. Burvenich. 1993. Preinfection chemotactic response of blood polymorphonuclear leukocytes to predict severity of Escherichia coli mastitis. J. Dairy Sci. 76:1568-1574.

Lam, T. J. G. M., Y. H. Schukken, F. J. Grommers, J. A. H. Smit, and A. Brand. 1993. Within-herd and between-herd variation in diagnosis of clinical mastitis in cattle. JAVMA 202:938-942.

Lam, T. J. G. M., J. H. Van Vliet, Y. H. Schukken, F. J. Grommers, A. Van Velden Russcher, H. W. Barkema, and A. Brand. 1997. The effect of discontinuation of postmilking teat disinfection in low somatic cell count herds. II. Dynamics of intramammary infections. Vet. Q. 19:47-53.

Leigh, J. A. 1999. Streptococcus uberis: A permanent barrier to the control of bovine mastitis? Vet. J. 157:225-238.

Lindström, U. B., H. Kenttämies, J. Arstila, and R. Tuovila. 1981. Usefulness of cell counts in predicting bovine mastitis. Acta Agric. Scand. 31:199-203.
Lohuis, J., Y. H. Schukken, P. A. J. Henricks, R. Heyneman, C. Burvenich, J. H. M. Verheijden, A. Vanmiert, and A. Brand. 1990. Preinfection functions of blood polymorphonuclear leukocytes and the outcome of experimental Escherichia coli mastitis in the cow. J. Dairy Sci. 73:342-350.

Martin, F., K. Failing, W. Wolter, B. Kloppert, and M. Zschock. 2002. Effect of parity and period of lactation on prevalence of mastitis pathogens in quarters with high somatic cell count (SCC $\geq$ 100.000/ml). Milchwissenschaft 57:183-187.

Nash, D. L., G. W. Rogers, J. B. Cooper, G. L. Hargrove, J. F. Keown, and L. B. Hansen. 2000. Heritability of clinical mastitis incidence and relationships with sire transmitting abilities for somatic cell score, udder type traits, productive life, and protein yield. J. Dairy Sci. 83:2350-2360.

Noordhuizen, J. P. T. M., K. Frankena, C. M. Van der Hoofd, and E. A. M. Graat. 1997. Measurement of disease frequency. Pages 6397 in Application of Quantitative Methods in Veterinary Epidemiology. Wageningen Pers, Wageningen, The Netherlands.

Pyörälä, S., L. Kaartinen, H. Kack, and V. Rainio. 1994. Efficacy of two therapy regimens for treatment of experimentally induced Escherichia coli mastitis in cows. J. Dairy Sci. 77:453-461.

SAS/STAT. 2001. User's guide. SAS Institute Inc., Cary, NC.

Schutz, M. M., L. B. Hansen, G. R. Steuernagel, and A. L. Kuck. 1990. Variation of milk, fat, protein, and somatic cells for dairy cattle. J. Dairy Sci. 73:484-493.

Sears, P. M., B. S. Smith, P. B. English, P. S. Herer, and R. N. Gonzalez. 1990. Shedding pattern of Staphylococcus aureus from bovine intramammary infections. J. Dairy Sci. 73:2785-2789.

Shoshani, E., G. Leitner, B. Hanochi, A. Saran, N. Y. Shpigel, and A. Berman. 2000. Mammary infection with Staphylococcus aureus in cows: progress from inoculation to chronic infection and its detection. J. Dairy Res. 67:155-169.

Smith, K. L., J. E. Hillerton, and R. J. Harmon. 2001. Guidelines on Normal and Abnormal Raw Milk Based on Somatic Cell Counts and signs of clinical mastitis. National Mastitis Council Inc., Arlington, VA. http://www.nmcowline.org/docs/abmilk.html.

Vaarst, M., and C. Enevoldsen. 1997. Patterns of clinical mastitis manifestations in Danish organic dairy herds. J. Dairy Res. 64:23-37.

Weller, J. I., A. Saran, and Y. Zeliger. 1992. Genetic and environmental relationships among somatic cell count, bacterial infection, and clinical mastitis. J. Dairy Sci. 75:2532-2540.

Wiggans, G. R., and G. E. Shook. 1987. A lactation measure of somatic cell count. J. Dairy Sci. 70:2666-2672. 